Special issue of the 3rd International Conference on Computational and Experimental Science and Engineering (ICCESEN 2016)

\title{
Investigation of Mechanical Properties of Butt Joints of DP800 Thin Zinc-Coated Steel Plates, CMT-Brazed Using Different Current Intensities
}

\author{
İ. $\operatorname{ACAR}^{a, *}, \mathrm{~V} \cdot \mathrm{SIKSIK}^{a}, \mathrm{~F} \cdot \mathrm{VAROL}^{a}$ AND S. ASLANLAR ${ }^{b}$ \\ ${ }^{a}$ Vocational School of Karasu, Sakarya University, Karasu, Sakarya, Turkey \\ ${ }^{b}$ Department of Metallurgical and Materials Engineering, Sakarya University, Sakarya, Turkey
}

\begin{abstract}
In this study, DP800 (dual phase) steel plates, having $1 \mathrm{~mm}$ thickness were joined by copper-based $(\mathrm{CuAl})$ wire using CMT-brazing (cold metal transfer) technique. Specimens were prepared in joining forms in butt joint configuration. CMT-brazing operations were done under nine different CMT-brazing current intensities of 40, 45, 50, 55, 60, 65, 70, 75 and $80 \mathrm{~A}$. CuAl8 wire, composed largely of copper, was used as the filler metal. Having accomplished the CMT-brazing operations, the tensile properties of joints, and micro- and macro-structures of joints were investigated in order to test the joinability of DP800 steel by CMT-brazing technique.
\end{abstract}

DOI: 10.12693/APhysPolA.132.849

PACS/topics: 81.05.Bx, 81.20.Vj

\section{Introduction}

Advanced high strength steels (AHSS) can find a wide range of applications in the automotive industry for reducing energy consumption and carbon emissions [1]. AHSS steels have a wide variety of steel types. Dualphase (DP), transformation induced plasticity (TRIP), complex-phase (CP), martensitic (MART) and twinning induced plasticity (TWIP) steels are categorized according to their microstructure and production shapes [2]. DP steels are widely used in the automotive industry due to their high tensile strength, good ductility, permanent yield and work hardening rate [3].

The galvanized DP800 automotive sheets are joined by different welding methods. Basak [4], Ozsarac [5], Aslanlar [6], and Akkas [7, 8] studied the resistance spot welding of galvanized steels in automotive applications. Lee [9] joined the DP780 steel parts using laser, TIG, and MAG welding methods.

In this research, CMT process of galvanized DP800 steel sheets was studied using copper-based filler. It is found that the joint strength is higher than that of the base materials. In present paper, CMT process of galvanized DP800 steels is studied with the emphasis on the microstructure and strengthening behavior and mechanisms of the joint.

\section{Experimental studies}

\subsection{Materials}

DP800 galvanized steel plates were used in this study. In the tests the galvanized steel plates had thickness of $1 \mathrm{~mm}$ and with of zinc coating of $7.5 \mu \mathrm{m}$. Steel plates

*corresponding author; e-mail: ibrahimacar@sakarya.edu.tr were cut to the size of $200 \times 200 \times 1 \mathrm{~mm}^{3}$. The sheets were positioned end to end, to allow between them a gap of $0.5 \mathrm{~mm}$, and were subjected to joining by CMT-brazing process. The filler metal was a solid wire with a diameter of $1 \mathrm{~mm}$, classified as AWS ERCuAl8, which is copperbased, with torch angle of $90^{\circ}$. Argon was used as the shielding gas at a flow rate of $12 \mathrm{l} / \mathrm{min}$.

\subsection{Methods and procedure}

The surface of the samples was cleaned by acetone before CMT-brazing operations. The current values for CMT-brazing operation were set to $40,45,50,55,60$, $65,70,75$ and $80 \mathrm{~A}$ in a butt joint configuration. Nine sets of welding parameters of different heat inputs were selected, as shown in Table I. The heat input, HI is calculated using Eqs. (1) and (2).

$$
\begin{aligned}
& \mathrm{HI}_{\text {linear }}=\frac{60 U I \eta}{V}, \\
& \mathrm{HI}_{\text {normalized }}=\frac{\mathrm{HI}_{\text {linear }}}{e},
\end{aligned}
$$

where $\eta_{\mathrm{CMT}}=0.7$ is the arc efficiency factor, $e$ is thickness $(\mathrm{mm}), U$ and $I$ are the mean values for the arc voltage and current intensity, respectively and $V$ $(\mathrm{cm} / \mathrm{min})$ is the CMT-brazing speed. All CMT-brazing tests were performed automatically on a machine equipped with a robot.

\section{Experimental results and discussion}

\subsection{Tensile tests}

The experiments have shown that most of tensile test specimens have fractured through the base metal of DP 800 galvanized steel. Processes, carried out at currents of $45,50,55,60,65,70,75$ and $80 \mathrm{~A}$, have shown that the strength of the joint zone was higher than that of the galvanized steel zone and the CuAl8 filler zone. It was obvious, that the joint zone was strengthened. At $40 \mathrm{~A}$ 
insufficient wetting has occurred as a result of low heat input. After examination of the strength values in Table I, it was observed that strength increases with the increase of current intensity, which is accompanied with the increase of heat input and wetting.

TABLE I

Effect of current density on tensile strength and heat input.

\begin{tabular}{c|c|c}
\hline $\begin{array}{c}\text { Current intensity } \\
{[\mathrm{A}]}\end{array}$ & $\begin{array}{c}\text { Tensile strength } \\
{[\mathrm{MPa}]}\end{array}$ & $\begin{array}{c}\text { Heat input } \\
{[\mathrm{J} / \mathrm{cm}]}\end{array}$ \\
\hline 40 & 499 & 812 \\
45 & 719 & 921 \\
50 & 730 & 1033 \\
55 & 756 & 1155 \\
60 & 763 & 1271 \\
65 & 734 & 1399 \\
70 & 745 & 1519 \\
75 & 744 & 1654 \\
80 & 744 & 1778
\end{tabular}

\subsection{Microhardness tests}

Figure 1 shows the measured microhardness values of the joints for different CMT-brazing current intensities. It is seen that microhardness value was highest in the heat affected zone and the hardness in the heat affected zone was higher than that of the copper filler and of the base material.
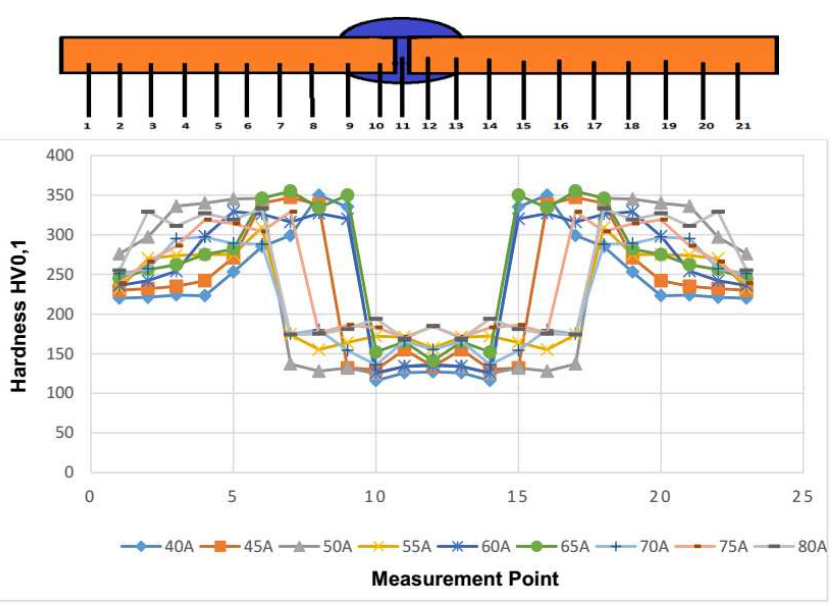

Fig. 1. Hardness profile in the heat affected zone in DP 800.

\subsection{Macro- and micro-structures}

Appearances of macro- and micro-structures of the brazing joints, for different current intensities, are shown in Fig. 2. The molten metal had wetted the steel much better when current intensity higher than $60 \mathrm{~A}$ was used.
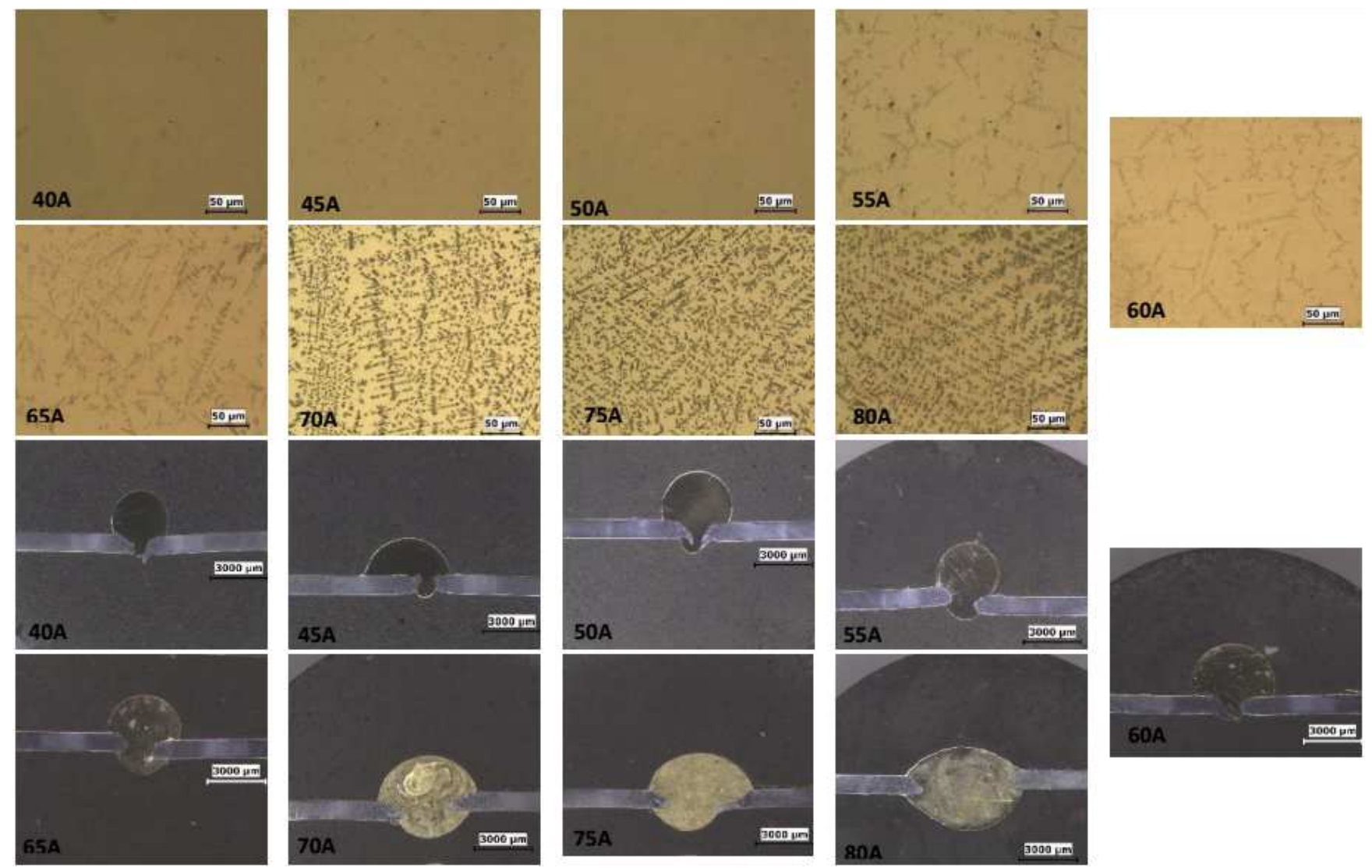

Fig. 2. Macro- and micro-appearance of the brazing joints for different current intensities. 
During the arc brazing process, it was observed that the number of dendrites increased on the surface of the joint zone. The action of these dendrites has caused micro iron particles to melt and migrate, and to become distributed throughout the filler metal zone.

\section{Conclusions}

This report presents an investigation on the effects of current intensity on the joint strength. The conclusions of this study are as follows;

- MIG-brazing method provided lower heat input in comparison with other fusion methods. The experiments show that most of tensile test specimens fractured inside the base metal of the DP800 galvanized steel.

- At $40 \mathrm{~A}$, insufficient wetting occurred, as a result of low heat input.

- It was observed, that strength decreased with the increase of current intensity. The best strength was achieved at current intensity of $60 \mathrm{~A}$.

\section{References}

[1] G.M. Xie, H.B. Cui, Z.A. Luo, W. Yu, J. Ma, G.D. Wang, J. Mater. Sci. Technol. 32, 326 (2016).

[2] Y. Liu, D. Dong, L. Wang, X. Chu, P. Wang, M. Jin, Mater. Sci. Eng. A 627, 296 (2015).

[3] S. Li, Y. Kang, G. Zhu, S. Kuang, Mater. Des. 85, 180 (2015).

[4] S. Basak, T.K. Pal, M. Shome, Int. J. Adv. Manuf. Technol. 82, 1197 (2016).

[5] U. Ozsarac, J. Mater. Eng. Perform. 21, 748 (2012).

[6] S. Aktas, U. Ozsarac, S. Aslanlar, Mater. Manuf. Process. 27, 756 (2012).

[7] N. Akkas, E. Ferik, E. İlhan, S. Aslanlar, Acta Phys. Pol. A 130, 60 (2016).

[8] N. Akkas, E. Fefik, E. İlhan, S. Aslanlar, Acta Phys. Pol. A 130, 142 (2016).

[9] J.H. Lee, S.H. Park, H.S. Kwon, G.S. Kim, C.S. Lee, Mater. Des. 64, 559 (2014). 